\title{
Generalized juvenile demodicosis in Shih-Tzu dog successfully treated with Moxidectin
}

\author{
Stefanie Bressan Waller 1*, Nielle Versteg 1, Peter de Lima Wachholz 1, Tábata Pereira Dias 1, Rebis de \\ Araújo 1, Marlete Brum Cleff 1
}

1 Department of Veterinary Clinics, Federal University of Pelotas, Pelotas, RS, Brazil.

*Corresponding author: Stefanie Bressan Waller. São Francisco da Califórnia street, 90, apartment 1001 - District of Higienópolis. Zip Code: 90550-080 - Porto Alegre, RS, Brazil. Phone: +55 (53) 9 9953-8241. E-mail: waller.stefanie@yahoo.com.br

Research Ethics Committee Approval (if necessary): Not applied.

Received on: Mar 21, 2021. Accepted on: Apr 7, 2021. Available online: Apr 8, 2021.
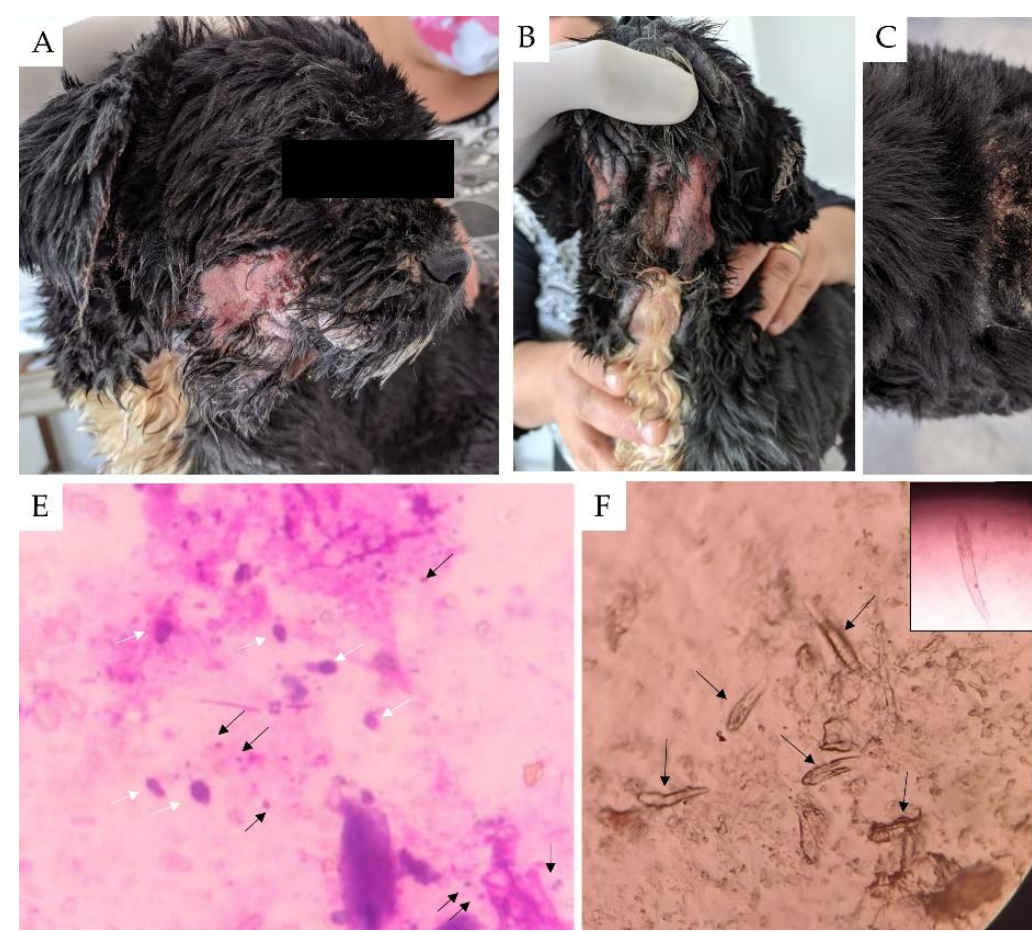
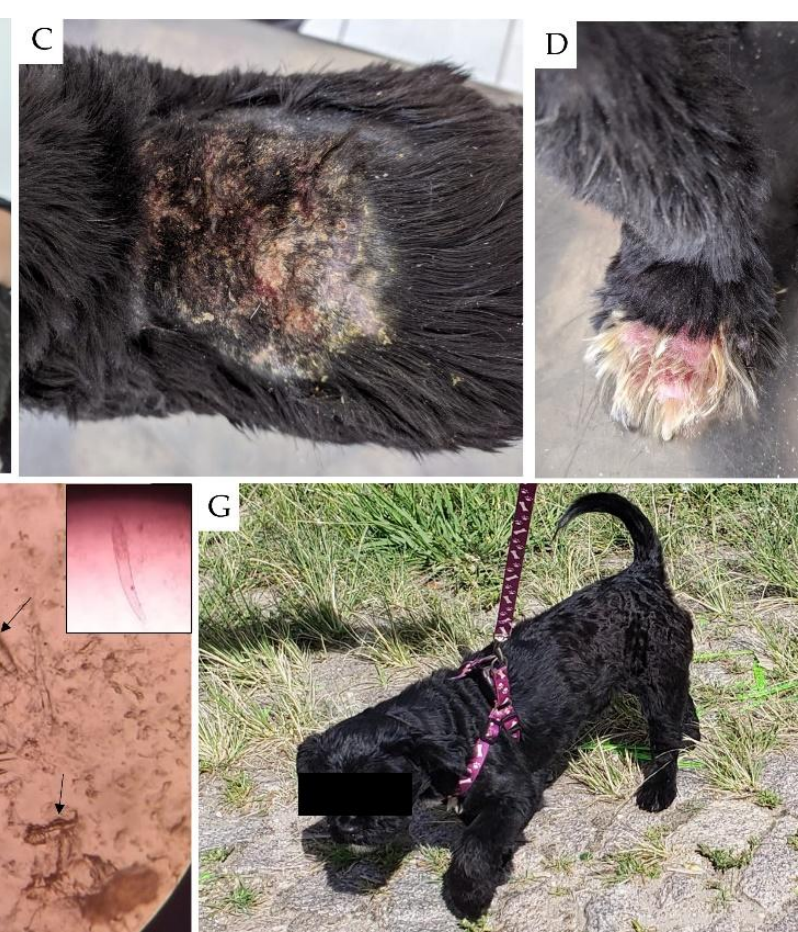

Figure 1. A 1-year-old Shih-Tzu male dog presenting intense itching and skin lesions of pyoderma, alopecia, and crusts in the cervical (A, B), dorsal (C), and interdigital of the left forelimb (D). Cytological tests (E, 40×) showed Gram-positive bacterial cocci (black arrows) and cells compatible with Malassezia sp. (white arrows). Deep skin scraping showed Demodex sp. in the adult stage (F, arrows, and detail in the right corner; 40x and 100x, respectively), confirming generalized juvenile demodicosis associated with secondary pyoderma. After 10 weeks of moxidectin therapy, the patient was cured $(G)$. 
Generalized juvenile demodicosis in Shih-Tzu dog successfully treated with Moxidectin

Skin disorders are one of the most common cases in Veterinary Medicine, mainly from infectious causes. A 1-yearold Shih-Tzu male dog, non-neutered weighing $5.750 \mathrm{~kg}$ was attended in the clinical ambulatory of the Hospital de Clínicas Veterinária (Faculty of Veterinary, Federal University of Pelotas) with a history of intense itching and skin lesions for about four months.

In the anamnesis, the owner reported that the dog had been treated with corticosteroids since the beginning of the clinical signs, due to the clinical suspicion of allergy. The signs improved at the beginning of the treatment, however, when interrupting the medication, remission of the cutaneous signs occurred. Normal appetite, as well as normal feces and urine, have been reported.

On physical examination, the dog presented skin lesions, alopecia, crusts in the cervical ventral (Fig. 1A e 1B) and dorsal (Fig. 1C) regions, as well as in the interdigital region of the left forelimb (Fig. 1D) with pyoderma. Considering the appearance of the lesions and their distributions, as well as itching, age, and absence of previous therapeutic response, the differential diagnosis included the following infectious diseases: demodicosis, leishmaniasis, dermatophytosis, and staphylococcosis, which could be isolated or associated.

A blood sample was collected to perform a rapid test for the screening of leishmaniasis (DPP®), Dual Path
Platform, Bio-Manguinhos, FIOCRUZ, Brazil), as well as a clinical sample for superficial and deep scraping for the study of mites, such as Sarcoptes spp. and Demodex spp., respectively, due to the preference of location in the epidermal structures. Sample collections by sterile swab and adhesive tape were also performed for cytology.

The results showed that the dog was negative for anti-Leishmania spp. antibodies and presented Gram-positive cocci and budding cells characteristic of Malassezia sp. (Fig. 1E). In the suspicion of demodicosis, a direct examination of the skin scrape on a slide containing a drop of mineral oil was performed. Microscopic analysis revealed the presence of several Demodex sp. in the adult stage (Fig. 1F), confirming the case of generalized juvenile demodicosis associated with secondary microbial infection.

Therefore, therapy with oral moxidectin (Cydectin $\AA, 0.5 \mathrm{mg} / \mathrm{kg}$, every 72 hours) was instituted for 4 weeks, associated with weekly baths with shampoo containing $2 \%$ chlorhexidine. Due to secondary pyoderma, the dog was also treated with amoxicillin with potassium clavulanate (Synulox®, $12.5 \mathrm{mg} / \mathrm{kg}$, every 12 hours, orally) for 10 days.

Every 15 days, the dog returned to the clinical ambulatory for skin scrapes for parasitic control and evaluation of clinical evolution, totaling three returns from clinical care, in which 
therapy with moxidectin was

maintained for a total of 10 weeks.

After this period, the dog returned for clinical evaluation, showing complete absence of lesion and the hair growth (Fig. 1G). No new tests were performed as there was no evidence of skin lesion, showing complete remission of clinical signs. Therefore, the therapy was adequate with clinical success in the present case of generalized juvenile demodicosis.

\section{References}

Not applicable.

Conflict of interest: The author declares no conflicts of interest.

Acknowledgements: To Prof. Dr. Martielo Ivan Gehrcke and Prof. Dr. Raqueli T. França (Hospital de Clínicas Veterinária, Federal University of Pelotas, Pelotas, Brazil) for laboratory support, and CAPES and CNPq for the scholarships.

Funding: List here the financial support received for the research.

How to cite this article: Waller SB, Versteg N, Wachholz PL, Dias TP, Araújo R, Cleff MB. Generalized juvenile demodicosis in Shih-Tzu dog successfully treated with Moxidectin. Brazilian Journal of Case Reports. 2021Abr-Jun;01(2):21-23. 